\title{
Genome sequencing and analysis of Salmonella enterica subsp. enterica serovar Stanley UPM 517: Insights on its virulence-associated elements and their potentials as vaccine candidates
}

\author{
Khalidah Syahirah Ashari $^{1}$, Najwa Syahirah Roslan ${ }^{2}$, Abdul Rahman Omar ${ }^{2,3}$, Mohd Hair Bejo ${ }^{2,3}$, Aini Ideris ${ }^{2,4}$, \\ Nurulfiza Mat Isa ${ }^{\text {Corresp. } 1,2}$ \\ ${ }^{1}$ Department of Cell and Molecular Biology, Faculty of Biotechnology and Biomolecular Sciences, Universiti Putra Malaysia, Serdang, Selangor, Malaysia \\ 2 Institute of Bioscience, Universiti Putra Malaysia, Serdang, Selangor, Malaysia \\ 3 Department of Veterinary Pathology and Microbiology, Faculty of Veterinary Medicine, Universiti Putra Malaysia, Serdang, Selangor, Malaysia \\ 4 Department of Veterinary Clinical Studies, Faculty of Veterinary Medicine, Universiti Putra Malaysia, Serdang, Selangor, Malaysia \\ Corresponding Author: Nurulfiza Mat Isa \\ Email address: nurulfiza@upm.edu.my
}

Salmonella enterica subsp. enterica serovar Stanley (S. Stanley) is a pathogen that contaminates food and is related to Salmonella outbreaks in a variety of hosts such as humans and farm animals through products like dairy items and vegetables. Despite the fact that several vaccines of Salmonella strains had been constructed, none of them was developed according to serovar Stanley up to this day. This study presents results of genome sequencing and analysis on our S. Stanley UPM 517 strain taken from fecal swabs of 21-day-old healthy commercial chickens in Perak, Malaysia and used S. enterica subsp. enterica serovar Typhimurium LT2 (S. Typhimurium LT2) as a reference to be compared with. First, sequencing and assembling of the Salmonella Stanley UPM 517 genome into a contiguous form were done. The work was then continued with scaffolding and gap filling. Annotation and alignment of the draft genome was performed with $S$. Typhimurium LT2. The other elements of virulence estimated in this study included pathogenicity islands, resistance genes, prophages, virulence factors, plasmid regions, restriction-modification sites and the CRISPR-Cas system. The S. Stanley UPM 517 draft genome had a length of $4,736,817$ bp with 4,730 CDS and 58 RNAs. It was discovered via genomic analysis on this strain that there were antimicrobial resistance properties towards a wide variety of antibiotics. Tcf and ste, the two fimbrial virulence clusters related with human and broiler intestinal colonizations which were not found in S. Typhimurium LT2, were atypically discovered in the S. Stanley UPM 517 genome. These clusters are involved in the intestinal colonization of human and broilers respectively. There were seven pathogenicity islands (SPIs) within the draft genome, which contained the virulence factors associated with 
Salmonella infection (except SPI-14). Five intact prophage regions, mostly comprising of the protein encoding Gifsy-1, Fels-1, RE-2010 and SEN34 prophages, were also encoded in the draft genome. Also identified were Type I-III restriction-modification sites and the CRISPR-Cas system of the Type I-E subtype. As this strain exhibited resistance towards numerous antibiotics, we distinguished several genes that had the potential for removal in the construction of a possible vaccine candidate to restrain and lessen the pervasiveness of salmonellosis and to function as an alternative to antibiotics. 
1 Genome sequencing and analysis of Salmonella enterica subsp. enterica serovar Stanley UPM

2 517: Insights on its virulence-associated elements and their potentials as vaccine candidates

4 Khalidah Syahirah Ashari ${ }^{1}$, Najwa Syahirah Roslan², Abdul Rahman Omar ${ }^{2,3}$, Mohd Hair Bejo ${ }^{2,3}$, $5 \quad$ Aini Ideris ${ }^{2,4} \&$ Nurulfiza Mat Isa ${ }^{1,2}$

$6{ }^{1}$ Department of Cell and Molecular Biology, Faculty of Biotechnology and Biomolecular Sciences, 7 Universiti Putra Malaysia, Serdang, Selangor, Malaysia.

$8 \quad$ Institute of Bioscience, Universiti Putra Malaysia, Serdang, Selangor, Malaysia

$9{ }^{3}$ Department of Veterinary Pathology and Microbiology, Faculty of Veterinary Medicine, 10 Universiti Putra Malaysia, Serdang, Selangor, Malaysia.

${ }^{4}$ Department of Veterinary Clinical Studies, Faculty of Veterinary Medicine, Universiti Putra

12 Malaysia, Serdang, Selangor, Malaysia.

14 Corresponding author:

15 Nurulfiza Mat Isa

16 Email address: nurulfiza@upm.edu.my 


\section{ABSTRACT}

Salmonella enterica subsp. enterica serovar Stanley ( $S$. Stanley) is a pathogen that contaminates food and is related to Salmonella outbreaks in a variety of hosts such as humans and farm animals through products like dairy items and vegetables. Despite the fact that several vaccines of Salmonella strains had been constructed, none of them was developed according to serovar Stanley up to this day. This study presents results of genome sequencing and analysis on our $S$. Stanley UPM 517 strain taken from fecal swabs of 21-day-old healthy commercial chickens in Perak, Malaysia and used $S$. enterica subsp. enterica serovar Typhimurium LT2 (S. Typhimurium LT2) as a reference to be compared with. First, sequencing and assembling of the Salmonella Stanley UPM 517 genome into a contiguous form were done. The work was then continued with scaffolding and gap filling. Annotation and alignment of the draft genome was performed with $S$. Typhimurium LT2. The other elements of virulence estimated in this study included pathogenicity islands, resistance genes, prophages, virulence factors, plasmid regions, restriction-modification sites and the CRISPR-Cas system. The $S$. Stanley UPM 517 draft genome had a length of 4,736,817 bp with 4,730 CDS and 58 RNAs. It was discovered via genomic analysis on this strain that there were antimicrobial resistance properties towards a wide variety of antibiotics. Tcf and ste, the two fimbrial virulence clusters related with human and broiler intestinal colonizations which were not found in $S$. Typhimurium LT2, were atypically discovered in the $S$. Stanley UPM 517 genome. These clusters are involved in the intestinal colonization of human and broilers respectively. There were seven pathogenicity islands (SPIs) within the draft genome, which contained the virulence factors associated with Salmonella infection (except SPI-14). Five intact prophage regions, mostly comprising of the protein encoding Gifsy-1, Fels-1, RE-2010 and SEN34 prophages, were also encoded in the draft genome. Also identified were Type I-III restriction-modification sites and the 
41 CRISPR-Cas system of the Type I-E subtype. As this strain exhibited resistance towards numerous

42 antibiotics, we distinguished several genes that had the potential for removal in the construction of a possible vaccine candidate to restrain and lessen the pervasiveness of salmonellosis and to function as an alternative to antibiotics.

\section{INTRODUCTION}

According to Crump et al. (2015) and Williamson et al. (2017), Salmonella enterica serovar Stanley ( $S$. Stanley) is a zoonotic non-typhoidal pathogenic microorganism responsible for food contamination. Characterized as O:4 (B) serogroup with 1,4,[5],12,[27]:d:1,2 antigenic formula (Grimont \& Weill, 2007), it is able to start salmonellosis outbreaks in humans by contaminating food-producing animals as well as eggs, dairy products, fruits and vegetables (Dahshan et al., 2010; Eng et al., 2015).

A few instances of salmonellosis outbreaks caused by $S$. Stanley had been reported before. The incidents were in Denmark and France in 2008. The Statens Serum Institute (SSI), Denmark, had found that $S$. Stanley was positioned the fifth most regular serovar which caused Salmonellosis in 3,657 cases. Meanwhile, Institut Pasteur (IP), France reported S. Stanley as being the $36^{\text {th }}$ serotype that was related with human salmonellosis out of 10,378 serotyped Salmonella. During the period of 2002-2007, Thailand recorded $11 \%$ cases of salmonellosis in humans due to this serovar (Hendriksen et al., 2009, 2012). In 2013 and 2014, the Center for Disease Control and Prevention (CDC) revealed cases of Salmonella infection due to $S$. Stanley involving 14 individuals from California, Nevada and Wyoming in the United States of America. Other than that, more recently 
63 similar cases were also reported in King County, Washington state, USA, infecting nine people in

642017 ("Salmonellosis outbreak caused by Salmonella Stanley - King County").

No death had been reported so far, nevertheless, the implications of this outbreak included

67 significant clinical symptoms and signs, for example, diarrhoea, abdominal cramps, vomiting, dehydration, nausea, muscle and joint pain as well as asthenia (Pastore et al., 2008). Hence, salmonellosis is still regarded as being of public health concern worldwide since it can affect the economies of a number of industrialized and developing nations and efforts are being made to put a stop to such outbreaks (Hardy, 2004; Eng et al., 2015).

Numerous measures have been put forward in the effort to lessen the spread of salmonellosis, such as by constructing antimicrobial agents. A number of studies which were done to know how susceptible $S$. Stanley was to antimicrobials revealed that isolates from humans, were highly resistant to ampicillin, chloramphenicol, streptomycin, sulfamethoxazole, trimethoprim and tetracycline but not so much to cephalosporins, gentamicin, ciprofloxacin and nalidixic acid with different degrees of resistance. (Bagger-Skjøt et al., 2007; Huang et al., 2007). Apart from that, Dahshan et al.'s (2010) study described that $S$. Stanley in bovine species appeared to be resistant to multi-drugs including ampicillin, chloramphenicol, streptomycin, sulfamethoxazole, oxytetracycline, trimethoprim and kanamycin. The existence of multi-drug resistance is of significant concern to global public health authorities due to the fact that it can possibly lessen the potency of the antibiotics. Thus, more appropriate intervention measures needed to be applied in order to efficiently decrease the spread of $S$. Stanley. One of the measures includes constructing 
vaccines that can fight against antimicrobial resistance while lowering the pathogenic and virulence features of $S$. Stanley (Clift \& Salisbury, 2017). Several Salmonella vaccines for poultry have been made which come in different forms such as spray, oral administration and so on (Varmuzova et al., 2016; Methner et al., 2004). But until today, not one of the vaccines developed used serovar Stanley as a base. Each of the serovars possesses a distinct virulence determinant that is able to trigger the immune response.

A review was done by Blakeway et al. (2017) on a number of virulence determinants of a pathogenic bacterium in the human nasopharynx, Moraxella catarrhalis. It is crucial to study factors that determine the virulence of $M$. catarrhalis in order to construct a vaccine to control the pervasiveness of the diseases caused by this pathogenic bacterium including otitis media (OM) in children as well as chronic obstructive pulmonary disease (COPD) in adults. In addition, a sequencing of Leptospira interrogans serovar Copenhageni strain Fiocruz L1-130 was conducted by Gamberini et al. (2005) to determine vaccine candidates of vaccine that might be effective against the cause of human leptospirosis: Leptospira. Wren (2000) explained that conducting sequencing on the entire genome of pathogenic microorganisms is a way to develop weakened vaccines. In order to construct weakened vaccines that are economical, this task can be accomplished through the finding and removal of virulence genes.

Thus, in order to better understand the genomic characteristics of $S$. Stanley's virulence and pathogenicity, we performed sequencing as well as analysis on our $S$. Stanley UPM 517 draft genome. The goal was to determine the elements associated with the virulence of $S$. Stanley UPM 
517 that might be deleted to develop a potential vaccine. The strain of $S$. Stanley UPM 517 from fecal swabs isolated in random from 21-day-old healthy commercial broiler chickens in Perak which were submitted to the Faculty of Veterinary Medicine, UPM for diagnosis, had been subjected to sequencing and annotation. The reference genome used for this study was Salmonella enterica subsp. enterica serovar Typhimurium str. LT2 (S. Typhimurium LT2), a significantly related and thoroughly studied complete genome. A number of analyses were performed on $S$. Stanley UPM 517, namely determination of resistance gene, pathogenic island, virulence factor, prophage, plasmid region, restriction modification site and the CRISPR-Cas system. The results we obtained could help in explaining the pathogenic features of serovar Stanley which would allow potential vaccines to be developed to lessen the prevalence of Salmonella outbreaks as well as to act as a substitute to antibiotics.

\section{MATERIALS AND METHODS}

\section{Genome sequencing and de novo assembly}

A strain sample of $S$. Stanley UPM 517 from fecal swabs of 21-day-old healthy commercial broiler chickens in Perak, Malaysia was sent to the Faculty of Veterinary Medicine, UPM. The Illumina Hiseq technology was used to sequence the genome and the CLC Genomics Workbench version 7.5.1 (QIAGEN Bioinformatics) with 16.7x of genome coverage was used for the assembly work.

BLASTn analysis was performed on the draft genome to get the reference genomes for scaffolding. Salmonella enterica subsp. enterica serovar Yovokome str. S-1850 (Accession No.: CP019418.1), Salmonella enterica subsp. enterica serovar Typhimurium strain LT2 (Accession No.: 
AE006468.2), strain CDC 2009K-2059 (Accession No.: CP014983.1), strain USDA-ARSUSMARC-1896 (Accession No.: CP014977.1) and strain USDA-ARS-USMARC-1898 (Accession No.: CP014971.2) were chosen as their characteristics relate the most with the reference genomes $\left(\mathrm{E}-\mathrm{value}=0.0\right.$, identity and query cover $=99 \%$, max score $\geq 3.837 \mathrm{e}^{+05}$ and total score $\geq 6.817 \mathrm{e}^{+05}$ ). MeDuSa (Bosi et al., 2015) and GapBlaster (De Sá et al., 2016) were respectively used for scaffolding and gap filling to further improve the $S$. Stanley UPM 517 contiguous sequences. The linker sequences (NNNNN) were added to connect the scaffolds and to construct a 'pseudogenome'.

\section{Gene prediction and functional annotation}

The RAST server was used to annotate the $S$. Stanley UPM 517 draft genome (Aziz et al., 2008) in which it identified potential genes and regions of coding via Glimmer (Kelley et al., 2012). On the other hand, RAST used the tRNAscan-SE (Lowe \& Eddy, 1996) to determine tRNA and the Niels Larsen's 'search_for_rnas' to determine rRNA. The annotated draft genome of $S$. Stanley UPM 517 had been deposited in the European Nucleotide Archive with accession number GCA_900834415. Homology searching by using BLAST was performed on Salmonella Stanley UPM 517 to get a complete genome that was thoroughly studied and closely related to $S$. Stanley UPM 517. Salmonella enterica subsp. enterica serovar Typhimurium str. LT2 (Accession No.: NC_003197.2) which had been isolated by McClelland et al., (2001) was chosen as a reference genome with 0.0 of E-value and $99 \%$ of identity. Analysis on the Orthologs (COGs) cluster was done by using OrthoVenn (Wang et al., 2015) with default parameters (E-value: 1e-5 and inflation value: 1.5$)$. 


\section{Whole genome alignment}

153 154 155 156

157

158 159 160

161

162

163 164 165

\section{Identification of resistance genes and pathogenicity islands}

Detection of acquired antimicrobial resistance genes was done using Resistance Gene Identifier (RGI) from the CARD database (Jia et al., 2017). Low levels of resemblance hits of genes were then removed. The identified resistance genes were validated via in vitro antimicrobial susceptibility testing which was carried out for six antimicrobials, namely ampicilin, cefotaxime, nalidixic acid, polymyxin B, tetracycline and trimethoprim-sulphamethoxazole. SPIFinder, which can be obtained from the Center for Genomic Epidemiology website (http://www.genomicepidemiology.org/), was used to identify Salmonella pathogenicity islands (SPIs) with $95 \%$ and $60 \%$ of identity threshold and minimum length, respectively. Then, BLAST analysis was performed on the predicted SPIs against the Virulence Factor Database (VFDB) (Chen et al., 2005) for identifying the existence of virulence factors in each SPI which included bacterial pathogens, toxins and virulence genes.

\section{Prediction of virulence factors, prophages and plasmid region}


171 With E-value of 1.0e-10, the same database was used to predict the virulence factors of the entire 172 draft genome. On the other hand, PHASTER (Arndt et al., 2016) was used to identify the sequence 173 of prophages contained in the genomes. Regions that scored above 90 were known as intact 174 prophage, regions that scored $70-90$ as questionable prophage and regions scoring below 70 as

175 incomplete prophage (Arndt et al., 2016). Next, VFDB was used to analyze the prophages that had 176 been identified to find the presence of possible virulence genes within their regions. PlasmidFinder 177 was then used to identify plasmid regions of the draft genome (Carattoli et al., 2014), and for 178 179 180

\section{Determination of Restriction-Modification sites and CRISPR}

Draft genome analysis was also carried out using a prediction tool constructed from the curated database REBASE (Roberts et al., 2015), Restriction-ModificationFinder (https://cge.cbs.dtu.dk/services/Restriction-ModificationFinder/) for identification of restrictionmodification sites. Analysis on CRISPR regions was also performed using CRISPRCasFinder (Couvin et al., 2018). The lowest level of evidence, 1, was used for the CRISPR regions with one to three spacers while the levels of evidence 2 to 4 were subjected to the other regions which were considered as true CRISPR. A similar tool with 'Subtyping' precision level was used to identify the associated proteins next to CRISPR (Cas proteins). The spacers between CRISPR arrays that had been determined were subsequently assigned to CRISPRTarget (Biswas et al., 2013) for the identification of potential protospacers against the Genbank-Phage and Refseq-Plasmid databases with cutoff score $\geq 20$. 


\section{RESULTS}

195

196

197

198

199

200

201

202

203

204

205

206

207

208

209

210

211

212

213

\section{General genome features}

Table 1 shows the $S$. Stanley UPM 517 and $S$. Typhimurium LT2 genome features in brief. The sequence of $S$. Stanley UPM 517 genome draft had an estimated length of 4,736,817 bp with GC content of $52.2 \%$ and 4,730 coding sequences (CDSs). As is shown in Figure 1, S. Stanley UPM 517 was detected to contain 54 tRNAs and four rRNAs which included two 5S rRNAs, one $16 \mathrm{~S}$ rRNA and one 23S rRNA.

\section{Cluster of orthologs groups (COGs)}

It was found that 4,027 out of the 4,033 COGs contained in Salmonella Stanley UPM 517 were also present in $S$. Typhimurium LT2 (Fig. 2). Six atypical orthologous clusters contained in the Salmonella Stanley UPM 517 genome consisted of 12 protein encoding carnitine transporter 7 , uncharacterized mitochondrial protein ymf21 and hypothetical proteins.

\section{Whole genome alignment}

Using Mauve's multiple genome alignments, it was found that the regions of $S$. Stanley UPM 517 and of $S$. Typhimurium LT2 were highly conserved (Fig. 3), but two locally collinear blocks (LCBs) of $S$. Stanley UPM 517 were reversed. However, $S$. Stanley UPM 517 and $S$. Typhimurium LT2 exhibited the highest identity (98.97\%) as shown by the ANI calculation prediction based on MUMmer by JSpeciesWS. 
215

216

217

218

219

220

221

222

223

224

225

226

227

228

229

230

231

232

233

234

235

\section{Antimicrobial resistance genes}

It was predicted that $S$. Stanley UPM 517 consisted of 27 genes coded to be resistant to a number of antibiotics such as fluoroquinolone, penicillin, macrolide, fosfomycin, peptide, aminocoumarin, aminoglycoside, monobactam, carbapenem, rifamycin, triclosan, glycylcycline, tetracycline, cephalosporin, phenicol, cephamycin, penems, carbapenem rhodamine, benzalkonium chloride, acycline, streptogramin and nitroimidazole (Table S1), among which, 16 were identified as having multi-drug resistance abilities. The major mechanism of the resistance against antibiotics is the efflux pump. It was found that $S$. Stanley UPM 517 was resistant against each of the six antibiotics (Table 2) based on the test of antimicrobial resistance via in vitro validation.

\section{Virulence factors and Salmonella Pathogenicity Islands (SPIs)}

A minimum of $994(20.96 \%)$ out of the 4,730 CDS annotated in $S$. Stanley UPM 517 were homologous to the virulence factors outlined in VFDB (Table S2). It was discovered that $S$. Stanley UPM 517 contained two fimbrae clusters, namely tcf that carried tcfABCD genes and ste that carried steABCDEF genes. However, these were not found in $S$. Typhimurium LT2. In addition, it was revealed that the $S$. Stanley UPM 517 genome contained seven pathogenicity islands, namely SPI-1, SPI-2, SPI-5, SPI-6, SPI-13, SPI-14 as well as centisome 63 pathogenicity island (C63PI). A total of 35 virulence factors encoding the required proteins for invasion of cells and secretion were carried in S. Stanley UPM 517's SPI-1 (Fig. 4A). A manual check on the VFDB results revealed two virulence factors clusters encoding for SPI-2 and SPI-6 (Fig. 4B and 4C). The 
236 SPI-5 of the same genome was also connected with six virulence factors that were involved in 237 translocation, namely pipB, ipgE, sopB/sigD, abpB, phoR and mprA proteins (Fig. 4D).

238 Meanwhile, iron transporter proteins (sitABCD) that encode for C63PI of $S$. Stanley UPM 517 239 genome (Fig. 4E), and gtrA and gtrB genes were discovered in SPI-13 (Fig. 4F). However, SPI24014 did not carry any of the virulence factors.

\section{Prophage regions}

Table S3 shows the identified prophages found within the DNA sequences, flanking between the attL and the attR attachment sites. Five regions of intact prophages were contained in Salmonella Stanley UPM 517 with a range of $24.0 \mathrm{~Kb}$ to $50.1 \mathrm{~Kb}$ and $46.80 \%$ to $51.64 \%$ of sizes and GC content, respectively (Fig.1). The $S$. Stanley UPM 517 and $S$. Typhimurium LT2 genomes both had Gifsy-1 and Fels-1 conserved. Although not present in $S$. Typhimurium LT2, a great amount of protein-encoding SEN34 and RE-2010 prophages were respectively present in abundance in region 1 and region 2. Most of the ORFs in region 1 encoded for the hypothetical protein, but some had predicted functions including tail fiber protein, ClpA-like protein and portal protein. A number of phage-encoded virulence factors were contained in the prophage regions as well, such as GogB protein which was present in prophage region 3, FljA in prophage region 2 and EspO1-1 in prophage region 4.

\section{Plasmid region}

There was no result obtained from identifying plasmid via PlasmidFinder, so an alternative approach as explained by Edwards \& Holt (2013) known as blast algorithm was carried out in this 
258

259

260

261

262

263

264

265

266

267

268

269

270

271

272

273

274

275

276

277

278

279

analysis. The results of PATRIC BLAST hits showed that five plasmid regions displayed high resemblance to $S$. Stanley UPM 517 regions, namely plasmid:2 and plasmid:4 of $S$. Seftenberg, pKp5-1 of Klebsiella pneumoniae KP5-1, pESI of Salmonella Infantis 119944 and p34978 of Enterobacter cloacae, each of which respectively showed $97 \%, 98 \%, 95 \%, 91 \%$ and $93 \%$ of identity resemblance.

\section{Restriction-Modification and CRISPR-Cas system}

A total of three R-M systems (RMS) were found in S. Stanley UPM 517 comprising of Type I, Type II and Type III. Cleaving was expected at the recognition motif GACNNNNNNNRTCC (the nucleotides underlined represented m6 sites) for Type I methyltransferase, M.Sen3124II; Type II methyltransferase, M.SenAboDcm and M.Sen1175III, recognized CㅁGG (the nucleotides underlined represented $\mathrm{m} 5$ sites) and ATGCA- (the nucleotides underlined represented $\mathrm{m} 6$ sites) motifs, respectively. Meanwhile, Type III restriction enzymes, M.Sen8391II as well as SenAZII, respectively recognized at CAGAG (the nucleotides underlined represented $\mathrm{m} 6$ site) and CAGAG motifs. However, the cleavage site of SenAZII was unknown.

Table 3 shows the results which summarized the CRISPR region predictions by CRISPRCasFinder. Based on the results, it was discovered that $S$. Stanley UPM 517 contained two CRISPRs at evidence of level 4 and also two at the lowest level of evidence. CRISPR 1 and CRISPR 2 displayed direct lengths of 29 bp, each with respectively 9 and 25 unique spacers, while the CRISPR 1 and CRISPR 2 loci were both found next to CRISPR-associated helicase, Cas2, Cas1, Cas6, Cas5, Cas7, Cse2, Cse1, Cas3 (Fig. 5). Meanwhile, the other CRISPR loci which only 
280 possessed one spacer each and Cas protein could not be found nearby these potential CRISPRs. A 281 total of 12 out of 36 spacers were recognized as protospacers (Table 4), 8 and 3 of which were 282 identified as homologs to plasmid sequences and phage sequences, respectively. In addition, one 283 spacer (Spacer 4) in CRISPR 1 was identified, harbouring within both plasmid and phage.

\section{DISCUSSION}

286

287 288

\section{Genome features}

In an attempt to study bacterial factors, the $S$. Stanley UPM 517's genome sequence was obtained from fecal swabs of 21-day-old healthy commercial broiler chickens in Perak, Malaysia. Table 2 shows in general, the genome characteristics of both $S$. Stanley UPM 517 and of $S$. Typhimurium LT2. It was discovered that the size of the Salmonella Stanley UPM 517 genome was rather small, possibly resulting from incomplete genome sequencing. In addition, there was a lower GC content level in $S$. Stanley UPM 517 than in $S$. Typhimurium LT2 by a small difference of $0.8 \%$, which indicated the homogeneity relationship of these strains. Apart from that, there was a substantial amount of intersecting orthologous clusters (4,040 clusters) in $S$. Stanley UPM 517 with $S$. Typhimurium LT2 which showed that these two strains might have the same functional capabilities.

\section{Whole genome alignment}

Alignment of the genome was also carried out on each strain (Fig.3). The two genomes appeared to have shared the majority of blocks which indicated a substantial amount of genetic information conserved between the strains. The predicted value of ANI between $S$. Stanley UPM 517 and other 
302 strains showed the same gene-content contained in the strains and thus they were highly related to 303 one another despite coming from different serovars.

\section{Plasmid regions}

306

307

308

309

310

311

312

313

314

315

316

317

318

319

320

321

322

323

Draft genome sequences usually contain plasmid sequences which act as mediators responsible for sending physiological traits to the bacterial host and causing bacterial evolution and adaptation to the environment (Shintani, Sanchez \& Kimbara, 2015). They also usually contain genes for antimicrobial resistance and virulence in Salmonella resulting in pathogenic features (García et al., 2014; Carattoli et al., 2014; Silva, Puente \& Calva, 2017). Plasmid:2 and plasmid:4 of $S$. Senftenberg NCTC10384 strain greatly resembled the S. Stanley UPM 517's regions. Based on these results, a conjugative transfer of plasmid:2 and plasmid:4 might have taken place between $S$. Stanley UPM 517 and $S$. Seftenberg strain NCTC10384 since these two had a similar environmental niche.

\section{Antimicrobial resistance genes}

A number of previous researches on multi-drug resistant $S$. Stanley had discovered that $S$. Stanley was resistant to some antibiotics such as ampicillin, chloramphenicol, streptomycin, sulfamethoxazole, trimethoprim, tetracycline, cephalosporins, gentamicin, ciprofloxacin, nalidixic acid, oxytetracycline and kanamycin to different extents (Bagger-Skjøt et al.; Huang et al., 2007; Dahshan et al., 2010). The prediction analysis that we conducted on resistance genes showed that the $S$. Stanley resistance phenotype against antibiotics had come into existence, thus widening the range of antibiotics that this strain is resistant to. 
325

326

327

328

329

330

331

332

333

\section{Virulence factors and SPIs}

Since the $S$. Stanley UPM 517 is resistant to a wider range of antibiotics, a practical way to lessen the pervasiveness of Salmonella outbreaks is required, for example, vaccination. According to Desin et al. (2013) and Revolledo et al. (2012), a great number of Salmonella vaccines had been developed by producing mutations or removing virulence determinants. An attenuated CVL30 derivative had been constructed by Cooper et al. (1994) using mutated aroA gene as a reference which would interfere with the key protein production in the aromatic biosynthetic pathway. Likewise, a $S$. Gallinarum oral vaccine had been developed by Penha Filho et al. (2010) by removing cobS and cbiA genes that disrupted cobalamin synthesis. After being tested, this vaccine was found to be effective towards $S$. Gallinarum and $S$. Enteritidis serovars. Also developed was a vaccine of live attenuated $S$. Typhimurium which had its cya and crp genes deleted. It was discovered that the vaccine managed to significantly reduce the challenge strain level in the ceca and could not be traced in the chicken spleen but was somehow ineffective towards $S$. Enteritidis (Hassan \& Curtiss, 1994). Thus, examining the characteristics of $S$. Stanley UPM 517's virulence is important to obtain a vaccine that is potent against a vast array of Salmonella.

The key roles of virulence factors include bacterial adherence, invasion, replication and survival within the host cells (Ribet \& Cossart, 2015). Salmonella Pathogenicity Islands (SPIs) are the particular regions in which several virulence factors are contained (Kaur \& Jain, 2012). SPIs are usually found close to tRNA with a distinct GC content. The SPIs in Salmonella probably gained its virulence factors via horizontal gene transfer, a characteristic that permits Salmonella to 
346

347

manifest its virulence purpose and which helps to infect the host cell with salmonellosis (Hensel 2004). The prediction analysis on SPIs showed that SPI-1, SPI-2, SPI-5, SPI-6, SPI-13, SPI-14 and C63PI were associated within the draft genome of $S$. Stanley UPM 517 which accomplished the task that we wanted done.

The virulence factor structures in SPI-1 for both $S$. Stanley UPM 517 and $S$. Typhimurium LT2 were conserved (Fig. 4A). It is known that SPI-1 in Salmonella enterica encodes for invasion, secretion system and translocation of proteins from the extracellular of Salmonella into the host cells (Gerlach \& Hensel, 2007). In the S. Stanley UPM 517 draft genome, SPI-1 was found to contain a number of effector proteins such as hilA, sipA, sipB, sptP, invA and invG. Bohez et al. (2007) discovered that a mutation of the SPI-1's major transcriptional regulator, hilA, which was responsible for the regulation of these effector proteins, could be a potential vaccine candidate for broilers against salmonellosis. They reported that invasion was successfully reduced by inoculating the non-invasive hilA mutant to the 1-day-old chickens. This inhibited colonization of the challenged strain in the intestines after 24 hours and this continued for nine days upon oral administration. Another study conducted by Matulova et al. (2012) reported the removal or deletion of the entire SPI-1 (SPI-1 mutant) and administered as an oral vaccine to 1 day-old chickens were able to block the colonization of the wild type $S$. Enteritidis, hence, protecting the poultry from the challenged strain. Dieye et al. (2009) obtained a similar finding in their study where 1-day-old chickens which had been infected with $S$. Typhimurium strain of SPI-1 mutant (the whole SPI-1 removed) successfully reduced the colonization of bacteria in the chicken's cecum and spleen. 
369 An effector protein, sipA, as discovered by Galkin et al. (2002), Higashide et al. (2002), Zhou et 370 al. (1999) and Zhou et al. (1999), was bound to the actin to modulate the host-cell small GTPases 371 and to regulate the signal transduction pathways. This functional manner subsequently activated 372 F-actin polymerization at the site of Salmonella adhesion and membrane ruffles formation, thus 373 facilitating the efficiency of Salmonella uptake. Other effector proteins, invA and invG, were 374 involved in the invasion of $S$. typhimurium to the epithelial cells as reported by Galan et al. (1992) 375 and Kaniga et al. (1994). Kubori et al. (2003) and McGhie et al. (2009) reported that an effector 376 protein sptP could survive longer in the host cell after the invasion and it was responsible for 377 terminating membrane ruffling and repaired the invaded-induced damage by reversing the 378 379 380 381 382 inflammatory mechanisms to ensure Salmonella intracellular survival in the invaded cell. Another study conducted by Chaudhuri et al. (2013) demonstrated that the sptP mutant in $S$. Typhimurium ST4/74 could reduce the colonization on chicks, pigs and cattle's intestine. Meanwhile, Hernandez et al. (2003) suggested an effector protein sipB played an important role in disrupting mitochondria and caused macrophage apoptosis, thereby leading to cell death. Thus, all the above mentioned effector proteins identified in $S$. Stanley UPM517 could be considered for removal to enable it to be a potential vaccine candidate.

Both $S$. Stanley UPM 517 and $S$. Typhimurium LT2's virulence factor distributions and organizations were conserved in SPI-1. However, three virulence factors encoding for SPI-2, namely ssaB (spiC), sseA and ssaS were not present in $S$. Stanley UPM 517. Studies performed by Ruiz-Albert et al. (2003) and Coombes et al. (2003) found that effector proteins such as sseB and sseD could not be translocated in the mutant sseA strains. They hypothesized that sseA might act as a chaperone required for the translocation of the SPI-2-encoded effector proteins to the host 
392 cells. Similarly, Freeman et al. (2002) discovered that ssaB (spiC) was needed to translocate the 393 SPI-2-encoded effector proteins such as sseB and sseC. However, in the S. Stanley UPM 517 394 genome, translocon proteins (sseB, sseC and sseD) were still present in the absence of sseA and $395 \mathrm{ssaB}$. This might indicate that the translocations of sseD and sseC of $S$. Stanley UPM 517 to the host cell were not dependent on sseA and ssaB respectively but might be dependent on sseB translocon. This finding was supported by a study performed by Chakravortty et al. (2005) who found that sseC and sseD proteins were dependent on sseB translocon as both sseC and sseD were not secreted by the sseB mutant in $S$. Typhimurium. Further studies must be conducted to validate the functionality of SPI-2 of S. Stanley UPM 517 and its proteins in depth. Another study focusing on intracellular survival capacity of $S$. Stanley UPM 517 in macrophages may also need to be performed to investigate whether the absence of ssaB, sseA and ssaS in SPI-2 would significantly affect the survival of $S$. Stanley in the host cells. Alternatively, ssaV in SPI-2 might also be considered for deletion before being used as a potential vaccine candidate as previously Figueira et al. (2013) showed that the mutation of this gene attenuated $S$. Typhimurium.

The sopB/sigD effector protein of SPI-5 also promoted the Salmonella invasion and membrane ruffling of the host cell in a phosphoinositide phosphatase manner and it was co-regulated together with the SPI-1 effector proteins and secreted by T3SS of SPI-1 (Knodler et al., 2002). On the other hand, the pipB of SPI-5 was released and translocated to the Salmonella-induced filaments and Salmonella-containing vacuole (SCV) upon infection, through T3SS of SPI-2 (Knodler et al., 2002). It was also described in a previous research that pipB of $S$. Typhimurium played a role in chicken enteropathogenesis (Morgan et al., 2004). Interestingly, the virulence factors that were earlier not related to any SPIs, namely mprA and abpB, were discovered in the SPI-5 of $S$. Stanley 
415 UPM 517. Besides, two virulence factors, mprA and abpB, which were previously not associated 416 with any SPIs, were predicted to be found in SPI-5 of S. Stanley UPM 517. Based on the results 417 listed from VFDB, these two virulence factors formerly originated from Mycobacterium vanbaalenii and Streptococcus gordonii respectively, suggesting that these virulence factors might have undergone horizontal gene transfer (HGT) events which allowed the transfer of mprA and abpB to Salmonella from other genera. According to He \& Zahrt (2005), mprA participated in the regulatory system to promote and maintain the growth of Mycobacterium tuberculosis at the persistent stage of infection within the host. Meanwhile, the abpB protein which encoded for amylase binding protein, might play a role in Salmonella Typhimurium LT2 infection and colonization by either degrading gylcan or by interacting with other effector proteins to establish biofilm formation (Arabyan, Huang \& Weimer, 2017; Chaudhuri et al., 2008).

The interesting finding was that $S$. Stanley UPM 517 appeared to have two uncommon fimbrial gene clusters, tcf and ste, which explained its distinctive virulence characteristics and therefore made it easier to understand the host-interaction of the $S$. Stanley UPM 517 genome. The collection of these fimbrial clusters might also give bits of knowledge on the construction of a vaccine candidate as they were exposed to the immune system. In $S$. Enteritidis, the ste cluster comprised of six fimbrial genes and played a role as a major cluster associated with chicken intestine colonization (Clayton et al., 2008). Initially, the tcf cluster was only discovered in typhoidal Salmonella, $S$. Typhi and $S$. Paratyphi A, and in a few non-typhoidal serovars like Choleraesuis, Heidelberg, Schwarzengrund, Virchow, Typhisuis, Muenchen and Montevideo (Townsend et al., 2001; Bronowski \& Winstanley, 2009). It had previously been described as contributing to human host colonization and more recent studies had been carried out in an effort to figure out features of 
438 its functional roles (Leclerc et al., 2016). Comprising of four virulence genes which encoded for 439 chaperone (tcfA), major subunit (tcfB), usher (tcfC) and adhesin (tcfD), it was inclusively 440 discovered in SPI-6 alongside the saf cluster and pagN. A study by Pezoa et al. (2013) discovered 441 that the SPI-6 mutation had reduced the gut and internal organ colonizations in chicks. Meanwhile, 442 it was found in another study by Carnell et al. (2007) that the reduction of gastrointestinal 443 colonization in pigs was caused by the mutation of the saf cluster. Two regions in the $S$. Stanley 444 UPM 517 draft genome were found to be homologous to the SPI-13 and SPI-14 of S. Gallinarum. 445 This result demonstrated that SPI-13 and SPI-14 were possibly being transferred from a phage or 446 plasmid through HGT. Two genes, gtrA and gtrB, were discovered in the SPI-13 of S. Stanley UPM 517 (Fig. 4). These genes encoded for bactoprenol-linked glucose translocase and

bactoprenol glucose transferase respectively in the modification of O-antigen structure (Davies et al., 2013). Nonetheless, none of ORFs were found in SPI-14 and thus its function was not thoroughly characterized.

Several SPIs were found missing in the S. Stanley UPM 517 draft genome, namely SPI-3, SPI-4, SPI-16 and SPI-9, but the important virulence factors that encoded them were detected such as SPI-3-encoded (misL), SPI-4-encoded (siiE), SPI-16-encoded (safBCD) and SPI-9-encoded (rpoS) which facilitated the adhesion of Salmonella to the host. CS54-encoded virulence factors such as shdA, ratB and sinH were found near to one another in the $S$. Stanley UPM 517 draft genome. Besides that, the fimbrial biosynthesis-encoded operons (csg, fim, lpf, bcf, saf, stb, stc, std, sth and sti) were also presented. Both CS54-encoded and fimbrial biosynthesis-encoded operons are responsible for colinization of mice intestine and facilitating the bacterial intestinal persistence in the mice respectively (Weening et al., 2005). 


\section{Prophage regions}

463

464 465

466

467

468

The viruses that infect bacteria are called prophages or bacteriophages (Sharma et al., 2017). They are functionally associated with the bacterial lifestyle, fitness, virulence, evolution and pathogenicity (Fortier \& Sekulovic, 2013; Fu et al., 2017). Gifsy-1 is a lambda-related prophage found in the $S$. Stanley UPM 517 draft genome which is predicted to play a role in the $S$. Stanley UPM 517 strain virulence since it was found to be harbouring gogB, a type III secretion virulence factor. However, GipA, an extensive phage encoded $S$. Typhimurium's virulence factor was absent in the Gifsy-1 of $S$. Stanley UPM 517. This is presumably a disadvantage to serovar Stanley since it is required for the survival of Peyer's patches (Stanley, Ellermeier \& Slauch, 2000). However, the reported salmonellosis cases caused by serovar Stanley were still continuously occurring in several countries, which downgraded the significance of GipA for virulence in the hosts

Fels-1 combined with Gifsy-1 prophage would create an improved bacterial virulence which when triggered might transfer their genetic materials to the host to get a better chance at survival. Such factors being distributed in Salmonella might assist in the construction of new pathogens (GarciaRussell, Elrod \& Dominguez, 2009). The Salmonella Stanley UPM 517 genome was also found to contain RE-2010 prophage which had been shown by a previous study to possess high nucleotide identity with the Fels-2 prophage (Colavecchio et al., 2017). It was also believed to function similarly as Fels-2 and was combined with Gifsy-1 and Fels-1 prophages in S. Stanley UPM 517. In addition, it was also found that a number of genes encoding SEN34 phage were contained in $S$. Stanley UPM 517. Having close connection with Siphoviridae phages, SEN34 phage is an 
483

484

485

486

487

488

489

490

491

492

493

494

495

496

497

498

499

500

501

502

503

504

505

unfamiliar temperate phage belonging to the Myoviridae family in terms of morphology (Mikalová et al., 2017). However, its significance in the Salmonella host is still unclear.

\section{Restriction-Modification and CRISPR-Cas systems}

The important role of the R-M system in bacteria is to fight invading DNA by providing immune defence mechanisms via methylation activity performed on its own DNA (Vasu \& Nagaraja, 2013). There were four types of R-M, namely Types I, II, III and IV (Roer et al., 2016), all of which were present in the $S$. Stanley UPM 517 genome except for Type IV. The CRISPR-Cas system plays a significant role in the bacterial adaptive immune system (Barrangou \& Marraffini, 2014; Burmistrz Michałand Pyrć, 2015; Rath et al., 2015) and its combination with the R-M system improves the bacteriophage's resistance level (Dupuis et al., 2013). It was found that the $S$. Stanley UPM 517 strain contained four CRISPR loci of 36 spacers each, 12 of which were protospacers identified in plasmids and phages (Table 4). These findings revealed that $S$. Stanley UPM 517 had the ability to generate immunity against several phages and plasmids. In addition, each of the 36 spacers was atypically identified in the S. Stanley UPM 517 genome which indicated rapid transformation of CRISPR 1 and CRISPR 2. In this study, an evaluation was conducted to identify the existence of Cas genes which are important for CRISPR activity as they encode for the crucial proteins of the immune system (Rath et al., 2015). They are usually found close to the CRISPR sites and work alongside crRNA by integrating the spacers into the CRISPR locus to improve bacterial immunity (Rath et al., 2015; Hille \& Charpentier, 2016). The CRISPR-Cas system's structure and distribution from S. Stanley UPM 517 belonged to Type I-E subtype (Makarova et al., 2011). The structure of the CRISPR-Cas system was also present in the S. Typhimurium LT2 genome (Fabre et al., 2012). Perhaps, the introduction of LacI to $S$. Stanley UPM 517 could be 
506

507 508 509 510

511

used as a vaccine candidate since according to Eswarappa et al. (2009) and Louwen et al. (2014), the introduction of LacI repressor could significantly induce the expression of the cas genes (cas1, cas 2 , cas 3 , cas5, cas 6 and cas7) and subsequently reduce the virulence of $S$. enterica by disrupting the expression of the virulence genes in SPI-2.

\section{CONCLUSION}

In conclusion, we have singled out several genes that we found to be suitable for removal in the development of potential vaccine candidates for controlling and reducing salmonella pervasiveness as well as to become a substitute to antibiotics. Removing these genes might help with the construction of a vaccine such as a live attenuated one, to fight against Salmonella. In addition, based on the comparisons made with the reference genome, we also found that our strain had the potential to colonize and spread through broilers as well as humans as it possessed the tcf and ste clusters. Apart from that, we also discovered that despite not having the secretion apparatus in SPI-2, this strain managed to survive being in the host. There is a need for further studies to measure the capacity of the intracellular survival of this serovar in the macrophages. More research on comparative genomics involving a vast variety of serovars should also be conducted to further characterize the currently little known serovar Stanley.

\section{ACKNOWLEDGEMENTS}

We would like to express our thanks to the Institute of Bioscience and Faculty of Biotechnology and Biomolecular Sciences for providing the computational facilities as well as to everyone who have extended their direct or indirect support towards this work. The authors would also like to 
528 thank Professor Soon Guan Tan, formerly Associate Editor of Elsevier Editorial System, Gene, for 529 proof reading the manuscript. 


\section{REFERENCES}

Arabyan N., Huang BC., Weimer BC. 2017. Amylases and Their Importance during Glycan Degradation: Genome Sequence Release of Salmonella Amylase Knockout Strains. Genome announcements 5. DOI: 10.1128/genomeA.00355-17.

Arndt D., Grant JR., Marcu A., Sajed T., Pon A., Liang Y., Wishart DS. 2016. PHASTER: a better, faster version of the PHAST phage search tool. Nucleic acids research 44:W16-21. DOI: $10.1093 /$ nar/gkw387.

Aziz RK., Bartels D., Best AA., DeJongh M., Disz T., Edwards RA., Formsma K., Gerdes S., Glass EM., Kubal M., Meyer F., Olsen GJ., Olson R., Osterman AL., Overbeek RA., McNeil LK., Paarmann D., Paczian T., Parrello B., Pusch GD., Reich C., Stevens R., Vassieva O., Vonstein V., Wilke A., Zagnitko O. 2008. The RAST Server: Rapid Annotations using Subsystems Technology. BMC Genomics 9:75. DOI: 10.1186/14712164-9-75.

Bagger-Skjøt L., Nielsen EM., Sandvang D., Ethelberg S., Monnet DL., Hammerum AM. 2007. Less frequent Salmonella serovars as a reservoir of antimicrobial resistance. Journal of Antimicrobial Chemotherapy. DOI: 10.1093/jac/dkm010.

Barrangou R., Marraffini LA. 2014. CRISPR-Cas systems: Prokaryotes upgrade to adaptive immunity. Molecular cell 54:234-44. DOI: 10.1016/j.molcel.2014.03.011.

Blakeway LV., Tan A., Peak IR., Seib KL. 2017. Virulence determinants of Moraxella catarrhalis: distribution and considerations for vaccine development. Microbiology 163(10):1371-1384.

Biswas, A., Gagnon, J. N., Brouns, S. J., Fineran, P. C., \& Brown, C. M. (2013). CRISPRTarget: bioinformatic prediction and analysis of crRNA targets. RNA biology 10(5), 817-27.

Bohez L., Ducatelle R., Pasmans F., Haesebrouck F., Van Immerseel F. 2007. Long-term colonisation-inhibition studies to protect broilers against colonisation with Salmonella Enteritidis, using Salmonella Pathogenicity Island 1 and 2 mutants. Vaccine 25:4235-4243. DOI: 10.1016/j.vaccine.2007.02.082. 
Bosi E., Donati B., Galardini M., Brunetti S., Sagot MF., Lió P., Crescenzi P., Fani R., Fondi M. 2015. MeDuSa: A multi-draft based scaffolder. Bioinformatics 31:2443-2451. DOI: 10.1093/bioinformatics/btv171.

Bronowski C., Winstanley C. 2009. Identification and distribution of accessory genome DNA sequences from an invasive African isolate of Salmonella Heidelberg: Research letter. FEMS Microbiology Letters 298:29-36. DOI: 10.1111/j.1574-6968.2009.01697.x.

Burmistrz Michałand Pyrć K. 2015. CRISPR-Cas Systems in Prokaryotes. Polish journal of microbiology 64:193-202.

Carattoli A., Zankari E., Garcia-Fernandez A., Larsen MV., Lund O., Villa L., Aarestrup FM., Hasman H. 2014. In Silico detection and typing of plasmids using plasmidfinder and plasmid multilocus sequence typing. Antimicrobial Agents and Chemotherapy 58:38953903. DOI: 10.1128/AAC.02412-14.

Carver T., Thomson N., Bleasby A., Berriman M., Parkhill J. 2009. DNAPlotter: Circular and linear interactive genome visualization. Bioinformatics 25:119-120. DOI: 10.1093/bioinformatics/btn578.

Chakravortty D., Rohde M., Jäger L., Deiwick J., Hensel M. 2005. Formation of a novel surface structure encoded by Salmonella Pathogenicity Island 2. The EMBO journal, 24(11):204352.

Chaudhuri B., Paju S., Haase EM., Vickerman MM., Tanzer JM., Scannapieco FA. 2008. Amylase-binding protein B of Streptococcus gordonii is an extracellular dipeptidylpeptidase. Infection and Immunity 76:4530-4537. DOI: 10.1128/IAI.00186-08.

Chaudhuri RR., Morgan E., Peters SE., Pleasance SJ., Hudson DL., Davies HM., Wang J., van Diemen PM., Buckley AM., Bowen AJ., Pullinger GD. 2013. Comprehensive assignment of roles for Salmonella typhimurium genes in intestinal colonization of food-producing animals. PLoS genetics, 9(4):e1003456.

Chen L., Yang J., Yu J., Yao Z., Sun L., Shen Y., Jin Q. 2005. VFDB: A reference database for bacterial virulence factors. Nucleic Acids Research 33:D325-D328. DOI: 10.1093/nar/gki008. 
Clayton DJ., Bowen AJ., Hulme SD., Buckley AM., Deacon VL., Thomson NR., Barrow PA., Morgan E., Jones MA., Watson M., Stevens MP. 2008. Analysis of the role of 13 major fimbrial subunits in colonisation of the chicken intestines by Salmonella enterica serovar Enteritidis reveals a role for a novel locus. BMC Microbiology 8:228. DOI: 10.1186/14712180-8-228.

Clift C., Salisbury DM. 2017. Enhancing the role of vaccines in combatting antimicrobial resistance. Vaccine 35:6591-6593. DOI: 10.1016/j.vaccine.2017.09.053.

Colavecchio A., D’Souza Y., Tompkins E., Jeukens J., Freschi L., Emond-Rheault JG., Kukavica-Ibrulj I., Boyle B., Bekal S., Tamber S., Levesque RC., Goodridge LD. 2017. Prophage integrase typing is a useful indicator of genomic diversity in Salmonella enterica. Frontiers in Microbiology 8:1283. DOI: 10.3389/fmicb.2017.01283.

Coombes BK., Brown NF., Kujat-Choy S., Vallance BA., Finlay BB. 2003. SseA is required for translocation of Salmonella pathogenicity island-2 effectors into host cells. Microbes and Infection 5:561-570. DOI: 10.1016/S1286-4579(03)00094-7.

Cooper GL., Venables LM., Woodward MJ., Hormaeche CE. 1994. Vaccination of chickens with strain CVL30, a genetically defined Salmonella enteritidis aroA live oral vaccine candidate. Infection and Immunity 62(11):4747-4754.

Couvin D., Bernheim A., Toffano-Nioche C., Touchon M., Michalik J., Néron B., C Rocha EP., Vergnaud G., Gautheret D., Pourcel C. 2018. CRISPRCasFinder, an update of CRISRFinder, includes a portable version, enhanced performance and integrates search for Cas proteins. Nucleic acids research 46:1-6. DOI: 10.1093/nar/gky425.

Crump JA., Sjölund-Karlsson M., Gordon MA., Parry CM. 2015. Epidemiology, Clinical Presentation, Laboratory Diagnosis, Antimicrobial Resistance, and Antimicrobial Management of Invasive Salmonella Infections. Clinical microbiology reviews 28:901-37. DOI: 10.1128/CMR.00002-15.

Dahshan H., Shahada F., Chuma T., Moriki H., Okamoto K. 2010. Genetic analysis of multidrug-resistant Salmonella enterica serovars Stanley and Typhimurium from cattle. Veterinary Microbiology 145:76-83. DOI: https://doi.org/10.1016/j.vetmic.2010.02.035. 
Davies MR., Broadbent SE., Harris SR., Thomson NR., van der Woude MW. 2013 Horizontally Acquired Glycosyltransferase Operons Drive Salmonellae Lipopolysaccharide Diversity. PLOS Genetics 9(6): e1003568. https://doi.org/10.1371/journal.pgen.1003568

Desin TS., Köster W., Potter AA. 2013. Salmonella vaccines in poultry: past, present and future. Expert review of vaccines 12(1):87-96.

Dieye Y., Ameiss K., Mellata M., Curtiss R. 2009. The Salmonella pathogenicity island (SPI) I contributes more than SPI2 to the colonization of the chicken by Salmonella enterica serovar Typhimurium. BMC Microbiology 9:3. DOI: 10.1186/1471-2180-9-3.

Dupuis M-Ė., Villion M., Magadán AH., Moineau S. 2013. CRISPR-Cas and restrictionmodification systems are compatible and increase phage resistance. Nature Communications 4:2087. DOI: 10.1038/ncomms3087.

Edwards DJ., Holt KE. 2013. Beginner's guide to comparative bacterial genome analysis using next-generation sequence data. Microbial Informatics and Experimentation 3:2. DOI: $10.1186 / 2042-5783-3-2$.

Eng SK., Pusparajah P., Ab Mutalib NS., Ser HL., Chan KG., Lee LH. 2015. Salmonella: A review on pathogenesis, epidemiology and antibiotic resistance. Frontiers in Life Science 8:284-293. DOI: 10.1080/21553769.2015.1051243.

Eswarappa SM., Karnam G., Nagarajan AG., Chakraborty S., Chakravortty D. 2009. lac repressor is an antivirulence factor of Salmonella enterica: its role in the evolution of virulence in Salmonella. PLoS One, 4(6):e5789.

Fabre L., Zhang J., Guigon G., Le Hello S., Guibert V., Accou-Demartin M., de Romans S., Lim C., Roux C., Passet V., Diancourt L., Guibourdenche M., Issenhuth-Jeanjean S., Achtman M., Brisse S., Sola C., Weill FX. 2012. Crispr typing and subtyping for improved Laboratory surveillance of Salmonella infections. PLoS ONE 7:e36995. DOI: 10.1371/journal.pone.0036995.

Figueira R., Watson KG., Holden DW., Helaine S. 2013. Identification of salmonella pathogenicity island-2 type III secretion system effectors involved in intramacrophage replication of S. enterica serovar typhimurium: implications for rational vaccine design. 
641

642

643

644

645

646

647

648

649

650

651

652

653

654

655

656

657

658

659

660

661

662

663

664 665

666

667

668

MBio 4(2):e00065-13.

Fortier L-C., Sekulovic O. 2013. Importance of prophages to evolution and virulence of bacterial pathogens. Virulence 4:354-365. DOI: 10.4161/viru.24498.

Freeman JA., Rappl C., Kuhle V., Hensel M., Miller SI. 2002. SpiC is required for translocation of Salmonella pathogenicity island 2 effectors and secretion of translocon proteins SseB and SseC. Journal of Bacteriology 184:4971-4980. DOI: 10.1128/JB.184.18.4971-4980.2002.

Fu T., Fan X., Long Q., Deng W., Song J., Huang E. 2017. Comparative analysis of prophages in Streptococcus mutans genomes. PeerJ 5:e4057. DOI: 10.7717/peerj.4057.

Fu Y., Galán JE. 1999. A Salmonella protein antagonizes Rac-1 and Cdc42 to mediate host-cell recovery after bacterial invasion. Nature, 401(6750):293.

Galan JE., Ginocchio C., Costeas P. 1992. Molecular and functional characterization of the Salmonella invasion gene invA: homology of InvA to members of a new protein family. Journal of bacteriology, 174(13):4338-49.

Galkin VE., Orlova A., VanLoock MS., Zhou D., Galán JE., Egelman EH. 2002. The bacterial protein SipA polymerizes G-actin and mimics muscle nebulin. Nature Structural and Molecular Biology, 9(7):518.

Gamberini M., Gómez RM., Atzingen MV., Martins EA., Vasconcellos SA., Romero EC., Nascimento AL. 2005. Whole-genome analysis of Leptospira interrogans to identify potential vaccine candidates against leptospirosis. FEMS microbiology letters, 244(2), 305313.

Garcia-Russell N., Elrod B., Dominguez K. 2009. Stress-induced prophage DNA replication in Salmonella enterica serovar Typhimurium. Infection, Genetics and Evolution 9:889-895. DOI: 10.1016/J.MEEGID.2009.05.017.

García P., Hopkins KL., García V., Beutlich J., Mendoza MC., Threlfall J., Mevius D., Helmuth R., Rodicio MR., Guerra B., Group on behalf of the M-V-NWP. 2014. Diversity of Plasmids Encoding Virulence and Resistance Functions in Salmonella enterica subsp. enterica Serovar Typhimurium Monophasic Variant 4,[5],12:i:- Strains Circulating in Europe. PLoS ONE 9:e89635. DOI: 10.1371/journal.pone.0089635. 
669

670

671

672

673

674

675

676

677

678

679

680

681

682

683

684

685

686

687

688

689

690

691

692

693

694

695

696

Gerlach RG., \& Hensel M. (2007). Salmonella pathogenicity islands in host specificity, host pathogen-interactions and antibiotics resistance of Salmonella enterica. Berliner und Munchener tierarztliche Wochenschrift 120:317-327.

Grimont PAD., Weill F-X. 2007. Antigenic Formulae of the Salmonella Serovars. Institut Pasteur, Paris, France: WHO Collaborating Centre for Reference and Research on Salmonella.

Guiney DG. 2005. The role of host cell death in Salmonella infections. Current topics in microbiology and immunology 289:131-50.

Hardy A. 2004. Salmonella: a continuing problem. Postgraduate medical journal 80:541-5. DOI: $10.1136 /$ pgmj.2003.016584.

Hassan JO., Curtiss, RIII. 1994. Development and evaluation of an experimental vaccination program using a live avirulent Salmonella typhimurium strain to protect immunized chickens against challenge with homologous and heterologous Salmonella serotypes. Infection and immunity 62(12):5519-5527.

He H., Zahrt TC. 2005. Identification and characterization of a regulatory sequence recognized by Mycobacterium tuberculosis persistence regulator MprA. Journal of Bacteriology 187:202-212. DOI: 10.1128/JB.187.1.202-212.2005.

Hendriksen RS., Bangtrakulnonth A., Pulsrikarn C., Pornruangwong S., Noppornphan G., Emborg H-D., Aarestrup FM. 2009. Risk Factors and Epidemiology of the Ten Most Common Salmonella Serovars from Patients in Thailand: 2002-2007. Foodborne Pathogens and Disease 6:1009-1019. DOI: 10.1089/fpd.2008.0245.

Hendriksen RS., Le Hello S., Bortolaia V., Pulsrikarn C., Nielsen EM., Pornruangmong S., Chaichana P., Svendsen CA., Weill F-XF-X., Aarestrup FM. 2012. Characterization of Isolates of Salmonella enterica Serovar Stanley, a Serovar Endemic to Asia and Associated with Travel. Journal of Clinical Microbiology 50:709-720. DOI: 10.1128/JCM.05943-11.

Hernandez LD., Pypaert M., Flavell RA., Galán JE. 2003. A Salmonella protein causes macrophage cell death by inducing autophagy. The Journal of cell biology, 163(5):1123-31.

Higashide W., Dai S., Hombs VP., Zhou D. 2002. Involvement of SipA in modulating actin 
697

698

699

700

701

702

703

704

705

706

707

708

709

710

711

712

713

714

715

716

717

718

719

720

721

722

723

724

dynamics during Salmonella invasion into cultured epithelial cells. Cellular microbiology, 4(6):357-65.

Hille F., Charpentier E. 2016. CRISPR-Cas: biology, mechanisms and relevance. Philosophical transactions of the Royal Society of London. Series B, Biological sciences 371:20150496. DOI: 10.1098/rstb.2015.0496.

Huang KY., Hong YW., Wang MH., Chu C., Su LH., Chiou CS., Chiu CH. 2007. Molecular epidemiology and antimicrobial susceptibility of Salmonella enterica serotype Stanley isolates in Taiwan. Journal of microbiology, immunology, and infection. 40:411-8.

Jia B., Raphenya AR., Alcock B., Waglechner N., Guo P., Tsang KK., Lago BA., Dave BM., Pereira S., Sharma AN., Doshi S., Courtot M., Lo R., Williams LE., Frye JG., Elsayegh T., Sardar D., Westman EL., Pawlowski AC., Johnson TA., Brinkman FSL., Wright GD., McArthur AG. 2017. CARD 2017: Expansion and model-centric curation of the comprehensive antibiotic resistance database. Nucleic Acids Research 45:D566-D573. DOI: 10.1093/nar/gkw1004.

Kaniga K., Bossio JC., Galán JE. 1994. The Salmonella typhimurium invasion genes invF and invG encode homologues of the AraC and PulD family of proteins. Molecular microbiology. 13(4):555-68.

Kaur J., Jain SK. 2012. Role of antigens and virulence factors of Salmonella enterica serovar Typhi in its pathogenesis. Microbiological Research 167:199-210. DOI: 10.1016/j.micres.2011.08.001.

Kelley DR., Liu B., Delcher AL., Pop M., Salzberg SL. 2012. Gene prediction with Glimmer for metagenomic sequences augmented by classification and clustering. Nucleic Acids Research 40:e9. DOI: $10.1093 / \mathrm{nar} / \mathrm{gkr1} 1067$.

Knodler LA., Celli J., Hardt WD., Vallance BA., Yip C., Finlay BB. 2002. Salmonella effectors within a single pathogenicity island are differentially expressed and translocated by separate type III secretion systems. Molecular Microbiology 43:1089-1103. DOI: 10.1046/j.13652958.2002.02820.x.

Kubori T., Galán JE. 2003. Temporal regulation of Salmonella virulence effector function by 
proteasome-dependent protein degradation. Cell, 115(3):333-42.

Leclerc JM., Quevillon EL., Houde Y., Paranjape K., Dozois CM., Daigle F. 2016. Regulation and production of Tcf, a cable-like fimbriae from Salmonella enterica serovar Typhi. Microbiology (United Kingdom) 162:777-788. DOI: 10.1099/mic.0.000270.

Louwen R., Staals RH., Endtz HP., van Baarlen P., van der Oost J. 2014. The role of CRISPRCas systems in virulence of pathogenic bacteria. Microbiol. Mol. Biol. Rev, 78(1):74-88.

Lowe TM., Eddy SR. 1996. TRNAscan-SE: A program for improved detection of transfer RNA genes in genomic sequence. Nucleic Acids Research 25:955-964. DOI: 10.1093/nar/25.5.0955.

Makarova KS., Haft DH., Barrangou R., Brouns SJJ., Charpentier E., Horvath P., Moineau S., Mojica FJM., Wolf YI., Yakunin AF., Van Der Oost J., Koonin E V. 2011. Evolution and classification of the CRISPR-Cas systems. Nature Reviews Microbiology 9:467-477. DOI: 10.1038/nrmicro2577.

Matulova M., Havlickova H., Sisak F., Rychlik I. 2012. Vaccination of chickens with Salmonella Pathogenicity Island (SPI) 1 and SPI2 defective mutants of Salmonella enterica serovar Enteritidis. Vaccine 30:2090-2097. DOI: 10.1016/j.vaccine.2012.01.050.

McClelland M., Sanderson KE., Spieth J., Clifton SW., Latreille P., Courtney L., Porwollik S., Ali J., Dante M., Du F., Hou S., Layman D., Leonard S., Nguyen C., Scott K., Holmes A., Grewal N., Mulvaney E., Ryan E., Sun H., Florea L., Miller W., Stoneking T., Nhan M., Waterston R., Wilson RK. 2001. Complete genome sequence of Salmonella enterica serovar Typhimurium LT2. Nature 413:852-856. DOI: 10.1038/35101614.

McGhie EJ., Brawn LC., Hume PJ., Humphreys D., Koronakis V. 2009. Salmonella takes control: effector-driven manipulation of the host. Current opinion in microbiology, 12(1):117-24.

Methner U., Barrow PA., Gregorova D., Rychlik I. 2004. Intestinal colonisation-inhibition and virulence of Salmonella phoP, rpoS and ompC deletion mutants in chickens. Veterinary microbiology 98(1):37-43.

Mikalová L., Bosák J., Hř́bková H., Dědičová D., Benada O., Šmarda J., Šmajs D. 2017. Novel 
753

754

755

756

757

758

759

760

761

762

763

764

765

766

767

768

769

770

771

772

773

774

775

776

777

778

779

780

temperate phages of Salmonella enterica subsp. salamae and subsp. diarizonae and their activity against pathogenic S. enterica subsp. enterica isolates. PLOS ONE 12:e0170734. DOI: 10.1371/journal.pone.0170734.

Morgan E., Campbell JD., Rowe SC., Bispham J., Stevens MP., Bowen AJ., Barrow PA., Maskell DJ., Wallis TS. 2004. Identification of host-specific colonization factors of Salmonella enterica serovar Typhimurium. Molecular Microbiology 54:994-1010. DOI: 10.1111/j.1365-2958.2004.04323.x.

Pastore R., Schmid H., Altpeter E., Baumgartner A., Hächler H., Imhof R., Sudre P., Boubaker K. 2008. Outbreak of Salmonella serovar Stanley infections in Switzerland linked to locally produced soft cheese, September 2006 - February 2007. Eurosurveillance 13:18979. DOI: 10.2807/ese.13.37.18979-en.

Penha Filho RAC., de Paiva JB., da Silva MD., de Almeida AM., Junior AB. 2010. Control of Salmonella Enteritidis and Salmonella Gallinarum in birds by using live vaccine candidate containing attenuated Salmonella Gallinarum mutant strain. Vaccine 28(16):2853-2859.

Rath D., Amlinger L., Rath A., Lundgren M. 2015. The CRISPR-Cas immune system: Biology, mechanisms and applications. Biochimie 117:119-128. DOI: 10.1016/J.BIOCHI.2015.03.025.

Revolledo L., Ferreira AJP. 2012. Current perspectives in avian salmonellosis: vaccines and immune mechanisms of protection. Journal of Applied Poultry Research 21(2):418-431.

Ribet D., Cossart P. 2015. How bacterial pathogens colonize their hosts and invade deeper tissues. Microbes and Infection 17:173-183. DOI: 10.1016/j.micinf.2015.01.004.

Richter M., Rosselló-Móra R., Oliver Glöckner F., Peplies J. 2015. JSpeciesWS: A web server for prokaryotic species circumscription based on pairwise genome comparison. Bioinformatics 32:929-931. DOI: 10.1093/bioinformatics/btv681.

Roberts RJ., Vincze T., Posfai J., Macelis D. 2015. REBASE—a database for DNA restriction and modification: enzymes, genes and genomes. Nucleic Acids Research 43:D298-D299. DOI: 10.1093/nar/gku1046.

Roer L., Hendriksen RS., Leekitcharoenphon P., Lukjancenko O., Kaas RS., Hasman H., 
Aarestrup FM. 2016. Is the Evolution of Salmonella enterica subsp. enterica Linked to Restriction-Modification Systems? mSystems 1:e0009-16. DOI: 10.1128/mSystems.0000916.

Ruiz-Albert J., Mundy R., Yu X-J., Beuzón CR., Holden DW. 2003. SseA is a chaperone for the SseB and SseD translocon components of the Salmonella pathogenicity-island-2-encoded type III secretion system. Microbiology 149:1103-1111. DOI: 10.1099/mic.0.26190-0.

De Sá PHCG., Miranda F., Veras A., De Melo DM., Soares S., Pinheiro K., Guimarães L., Azevedo V., Silva A., Ramos RTJ. 2016. GapBlaster - A graphical gap filler for prokaryote genomes. PLoS ONE 11:e0155327. DOI: 10.1371/journal.pone.0155327.

Salmonellosis outbreak caused by Salmonella Stanley - King County. Available at https://www.kingcounty.gov/depts/health/communicable-diseases/diseasecontrol/outbreak/salmonella-stanley.aspx (accessed July 4, 2018).

Sharma S., Chatterjee S., Datta S., Prasad R., Dubey D., Prasad RK., Vairale MG. 2017. Bacteriophages and its applications: an overview. Folia Microbiologica 62:17-55. DOI: 10.1007/s12223-016-0471-X.

Shintani M., Sanchez ZK., Kimbara K. 2015. Genomics of microbial plasmids: classification and identification based on replication and transfer systems and host taxonomy. Frontiers in microbiology 6:242. DOI: 10.3389/fmicb.2015.00242.

Silva C., Puente JL., Calva E. 2017. Salmonella virulence plasmid: pathogenesis and ecology. Pathogens and Disease 75. DOI: 10.1093/femspd/ftx070.

Stanley TL., Ellermeier CD., Slauch JM. 2000. Tissue-specific gene expression identifies a gene in the lysogenic phage Gifsy-1 that affects Salmonella enterica serovar typhimurium survival in Peyer's patches. Journal of bacteriology 182:4406-13.

Townsend SM., Kramer NE., Edwards R., Baker S., Hamlin N., Simmonds M., Stevens K., Maloy S., Parkhill J., Dougan G., Bäumler AJ. 2001. Salmonella enterica serovar Typhi possesses a unique repertoire of fimbrial gene sequences. Infection and immunity 69:2894901. DOI: 10.1128/IAI.69.5.2894-2901.2001.

Varmuzova K., Faldynova M., Elsheimer-Matulova M., Sebkova A., Polansky O., Havlickova 
H., Sisak F., Rychlik I. 2016. Immune protection of chickens conferred by a vaccine consisting of attenuated strains of Salmonella Enteritidis, Typhimurium and Infantis. Veterinary research 47(1):94.

Vasu K., Nagaraja V. 2013. Diverse functions of restriction-modification systems in addition to cellular defense. Microbiology and molecular biology reviews : MMBR 77:53-72. DOI: 10.1128/MMBR.00044-12.

Wang Y., Coleman-Derr D., Chen G., Gu YQ. 2015. OrthoVenn: A web server for genome wide comparison and annotation of orthologous clusters across multiple species. Nucleic Acids Research 43:W78-W84. DOI: 10.1093/nar/gkv487.

Weening EH., Barker JD., Laarakker MC., Humphries AD., Tsolis RM., Bäumler AJ. 2005. The Salmonella enterica serotype typhimurium lpf, bcf, stb, stc, std, and sth fimbrial operons are required for intestinal persistence in mice. Infection and Immunity 73:3358-3366. DOI: 10.1128/IAI.73.6.3358-3366.2005.

Williamson DA., Lane CR., Easton M., Valcanis M., Strachan J., Veitch MG., Kirk MD., Howden BP. 2017. Increasing antimicrobial resistance in non-typhoidal Salmonella in Australia, 1979 - 2015. Antimicrobial Agents and Chemotherapy:AAC.02012-17. DOI: 10.1128/AAC.02012-17.

Wren BW. 2000. Microbial genome analysis: insights into virulence, host adaptation and evolution. Nature Reviews Genetics 1(1):30.

Zhou D., Mooseker MS., Galán JE. An invasion-associated Salmonella protein modulates the actin-bundling activity of plastin. 1999. Proceedings of the National Academy of Sciences, 31;96(18):10176-81.

Zhou D., Mooseker MS., Galán JE. 1999. Role of the S. typhimurium actin-binding protein SipA in bacterial internalization. Science, 26;283(5410):2092-5. 


\section{Table $\mathbf{1}$ (on next page)}

General genome characteristics of S. Stanley UPM 517 and S. Typhimurium LT2 genome. 


\begin{tabular}{|l|c|c|}
\hline Features & S. Stanley UPM 517 & S. Typhimurium LT2 \\
\hline Status & Draft & Complete \\
\hline Genome size (bp) & $4,736,817$ & $4,857,432$ \\
\hline GC content (\%) & 52.2 & - \\
\hline Contigs & 94 & - \\
\hline Scaffolds & 9 & 8,489 \\
\hline Total no. of CDS & 4,730 & 85 \\
\hline Total no. of tRNA & 54 & 22 \\
\hline Total no. of rRNA & 4 & (McClelland et al., 2001) \\
\hline References & This work & - \\
\hline
\end{tabular}




\section{Table 2 (on next page)}

Antimicrobial susceptibility testing of S. Stanley UPM 517.

The diameter of inhibition zones were measured and were categorized according to the following categories: $\mathrm{S}=$ Susceptible, I=Intermediate, $\mathrm{R}=$ Reistant. Salmonella Stanley UPM 517 was resistant towards all the tested antibiotics. 


\begin{tabular}{|c|c|c|c|c|}
\hline \multirow{2}{*}{ Antibiotic } & \multicolumn{2}{|c|}{ Zone diameter breakpoint (mm) } & \multirow{2}{*}{ Results (mm) } \\
\cline { 2 - 5 } & S $\geq$ & I & R & \\
\hline Ampicilin (amp) & 15 & - & 14 & 10.0 \\
\hline Cefotaxime (ctx) & 30 & $24-29$ & 23 & 14.0 \\
\hline Nalidixic acid (na) & 18 & - & 17 & 11.0 \\
\hline $\begin{array}{c}\text { Polymyxin B (pb) } \\
\text { Tetracycline (te) }\end{array}$ & 15 & 15 & 14 & 7.5 \\
\hline $\begin{array}{c}\text { Trimethoprim- } \\
\text { sulphamethoxazole } \\
\text { (sxt) }\end{array}$ & 17 & $14-16$ & 13 & 13.5 \\
\hline
\end{tabular}

1 


\section{Table 3 (on next page)}

CRISPR regions identified in S. Stanley UPM 517 genome and its properties.

CRISPR locus with evidence level 1-2 are considered as invalid candidates while locus with evidence level 3-4 are assigned as highly predicted candidates. Both CRISPR 1 and CRISPR 2 contained 29 bp of direct repeats (DR). Cas cassette was found between CRISPR 1 and CRISPR 2 locus, locating from 274,100 bp to 282,550 bp of the whole genome. 


\begin{tabular}{|c|c|c|c|c|c|c|}
\hline $\begin{array}{c}\text { CRISPR } \\
\text { locus }\end{array}$ & $\begin{array}{c}\text { Evidence } \\
\text { level }\end{array}$ & $\begin{array}{c}\text { DR length } \\
\text { (bp) }\end{array}$ & $\begin{array}{c}\text { No. of } \\
\text { spacers }\end{array}$ & $\begin{array}{c}\text { Conservation } \\
\text { spacer }\end{array}$ & Start & End \\
\hline CRISPR 1 & 4 & 29 & 9 & $0 \%$ & 273,426 & 274,003 \\
\hline CRISPR 2 & 4 & 29 & 25 & $0 \%$ & 290,135 & 291,688 \\
\hline CRISPR 3 & 1 & 26 & 1 & $100 \%$ & 614,013 & 614,115 \\
\hline CRISPR 4 & 1 & 25 & 1 & $100 \%$ & $4,725,915$ & $4,725,991$ \\
\hline
\end{tabular}

1 


\section{Table 4 (on next page)}

Identified protospacers within CRISPR arrays of S. Stanley UPM 517 with their scores. 


\begin{tabular}{|c|c|c|c|c|}
\hline CRISPR & Spacer & Prophage/plasmid & Accesion Number & Score \\
\hline \multirow{11}{*}{ CRISPR 1} & Spacer 2 & Plasmid pSF83666a of Sinorhizobium fredii strain CCBAU 83666 & NZ_CP023072.1 & 20 \\
\hline & \multirow{6}{*}{ Spacer 4} & Plasmid pOXA10 020023 of Escherichia coli strain SCEC020023 & NZ CP025944.2 & 32 \\
\hline & & Plasmid pCFR-9161 of Citrobacter freundii complex sp. CFNIH3 & NZ_CP026237.1 & 32 \\
\hline & & Plasmid unitig_2 of Escherichia coli strain AR_0114 & NZ_CP021734.1 & 32 \\
\hline & & Plasmid unamed 2 of Pantoea ananatis strain $97-1$ & NZ_CP020945.1 & 20 \\
\hline & & Gordonia phage Eyre & KX557277 & 20 \\
\hline & & Plasmid pDSJ10 of Pantoea stewartii subsp. stewartii DC283 & NZ_CP017591.1 & 20 \\
\hline & \multirow{4}{*}{ Spacer 8} & Plasmid byi_1p of Burkholderia sp. YI23 & NC_016626.1 & 20 \\
\hline & & Plasmid p1 of Burkholderia sp. RPE67 & NZ_AP014579.1 & 20 \\
\hline & & Plasmid pkk1 of Burkholderia sp. KK1 & NZ_CP016002.1 & 20 \\
\hline & & Plasmid AbAZ39_p1 of Azospirillum brasilense strain Az39 & NZ_CP007794.1 & 20 \\
\hline \multirow{5}{*}{ CRISPR 2} & Spacer 3 & plasmid unnamed1 of Azospirillum sp. M2T2B2 & NZ_CP029830.1 & 20 \\
\hline & Spacer 4 & Cronobacter phage ESSI-2 & HQ110083 & 20 \\
\hline & Spacer 8 & $\begin{array}{l}\text { Plasmid:2 of Salmonella enterica subsp. enterica serovar Seftenberg } \\
\text { NCTC10384 }\end{array}$ & NZ_LN868944.1 & 32 \\
\hline & \multirow{2}{*}{ Spacer 9} & Erwinia phage Pavtok & MH426726 & 20 \\
\hline & & Erwinia phage PEp14 & JN585957 & 24 \\
\hline
\end{tabular}




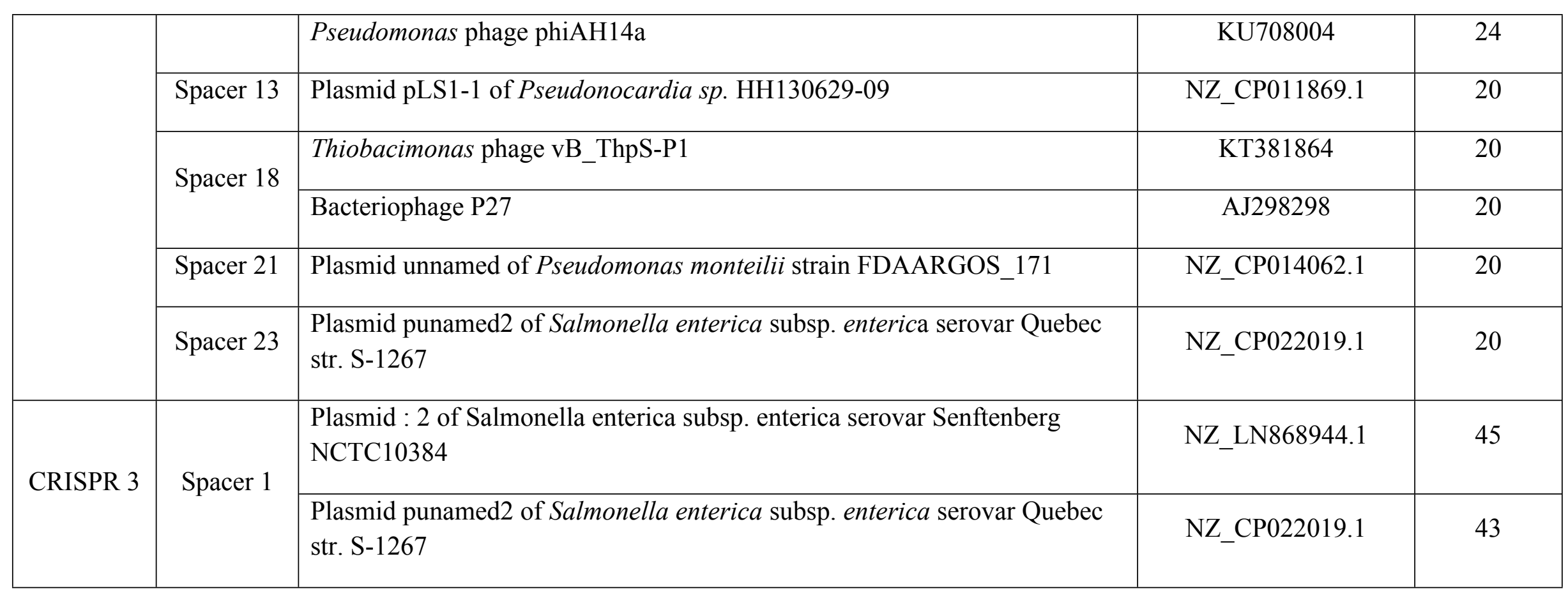


Figure 1

Circular representation of S. Stanley UPM 517 draft genome.

Tracks from the outermost are as follows: Forward CDS, reverse CDS, RNA (blue represents tRNA and red represents rRNA), SPIs, virulence factors, CRISPR-Cas system (green indicates CRISPR region and yellow indicates cas genes), plasmid regions, antimicrobial genes and prophage regions. The two inner tracks are $\mathrm{G}+\mathrm{C}$ content and $\mathrm{GC}$ bias (innermost track). The circular map was generated by using DNAPlotter (Carver et al., 2009). 


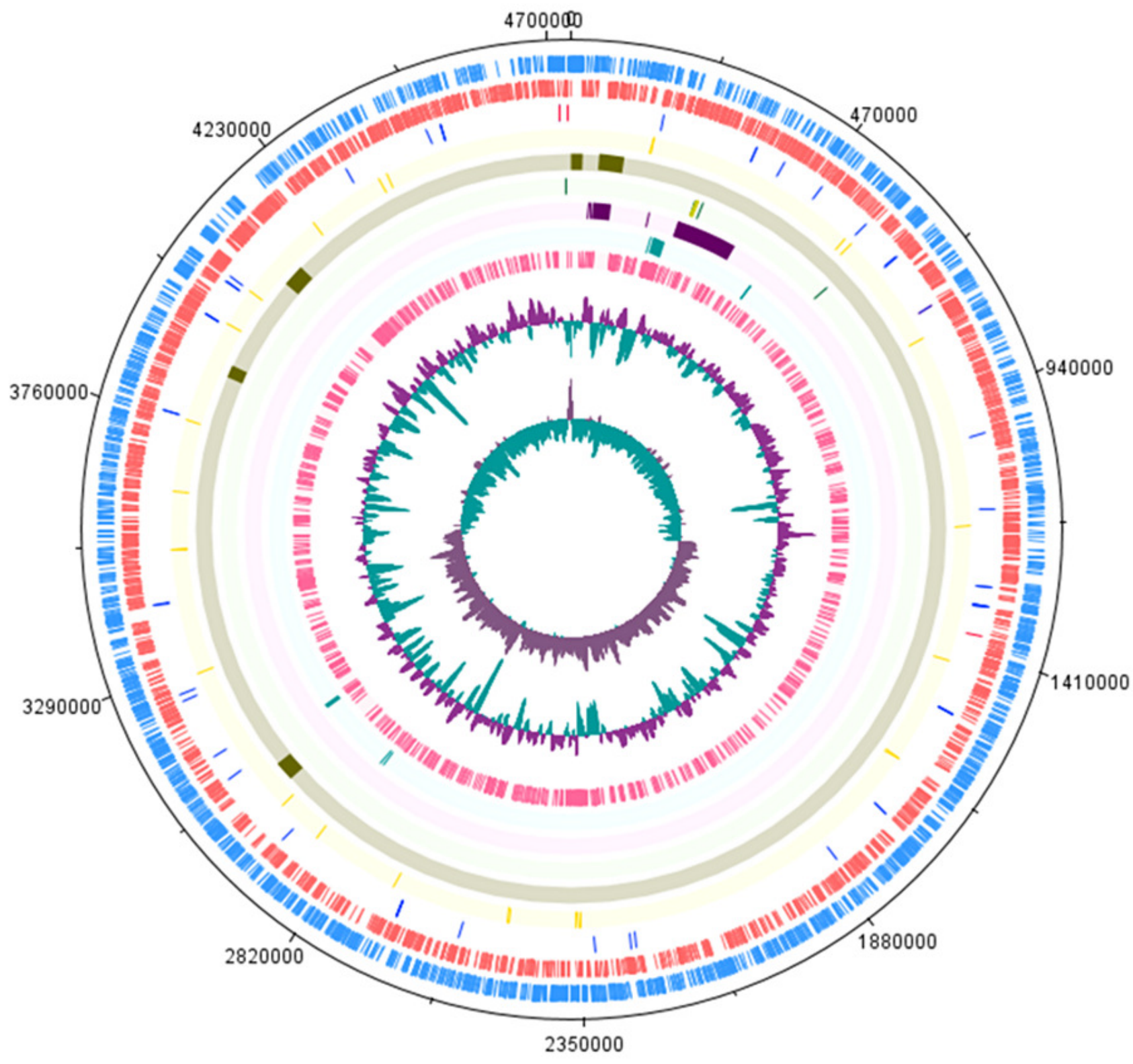


Figure 2

Unique and shared COGs between S. Stanley UPM 517 and S. Typhimurium LT2

Both strains shared higher number of COGs, showing that they carry similar functional capabilities.

\section{S. Stanley UPM 517}

S. Typhimuirum LT2

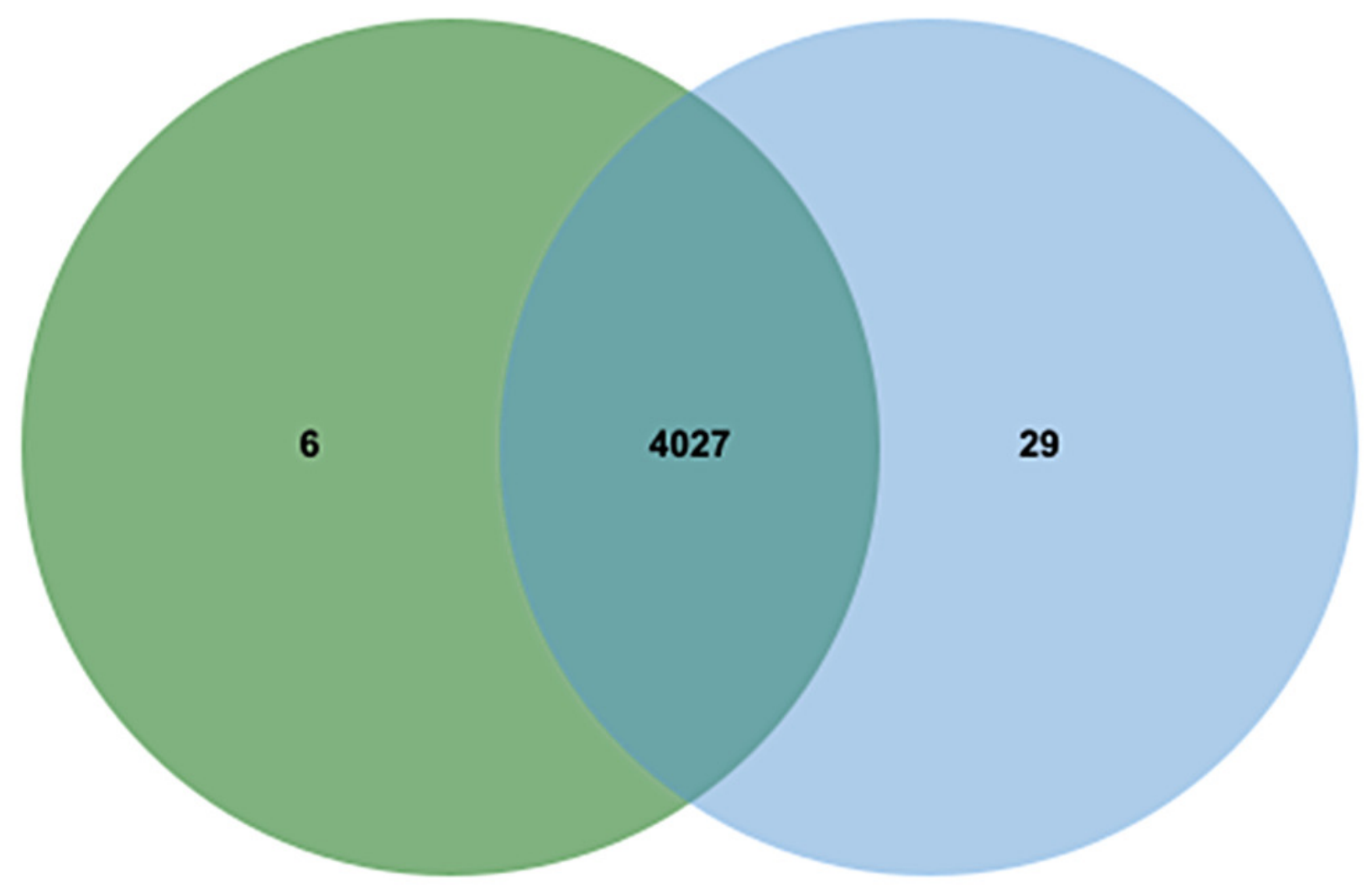




\section{Figure 3}

Whole genome alignment between S. Stanley UPM 517 and S. Typhimurium LT2 by progressive Mauve

The lines connecting between blocks indicate the blocks were conserved between both $S$.

Stanley UPM 517 and S. Typhimurium LT2 genome. A slightly sequence rearrangement and inversed block was also presented. The inversed block indicates reverse complement orientation of S. Stanley UPM 517 corresponds to S. Typhimurium LT2 genome

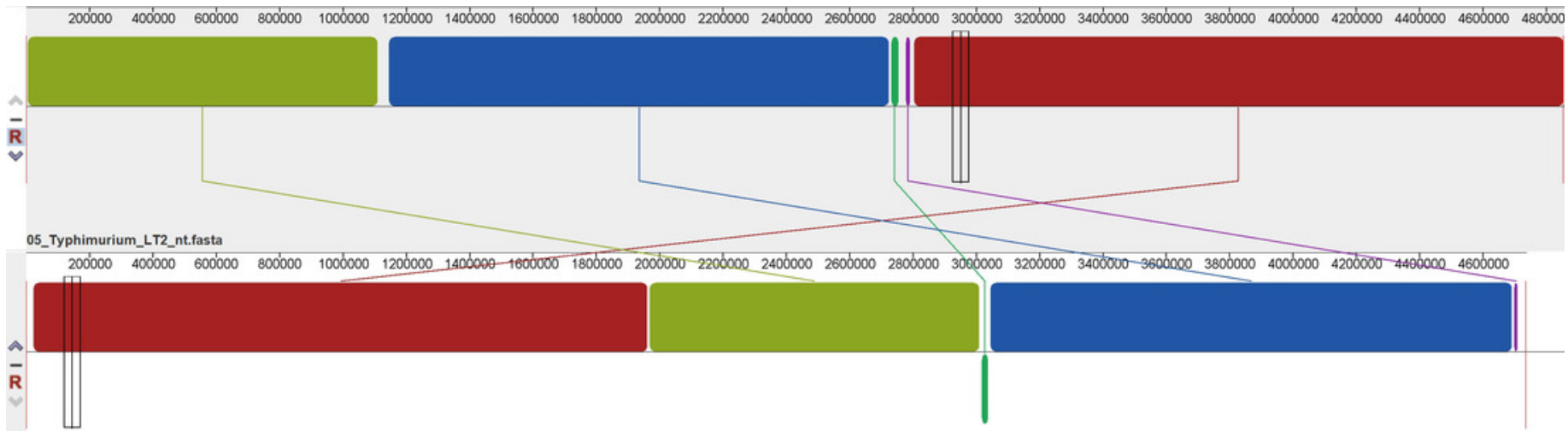


Figure 4

Genetic organization of virulence factors in (A) SPI-1, (B) SPI-2, (C) SPI-6, (D) SPI-5, (E) C63PI and (F) SPI-13

HP indicates hypothetical protein. The linear map was generated by using DNAPlotter (Carver et al., 2009).

A)

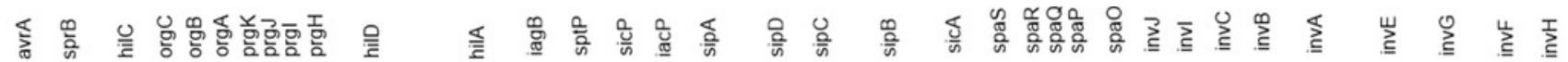

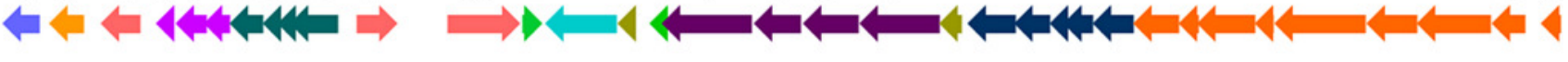

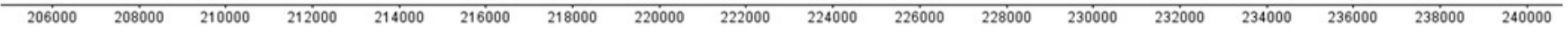

B)

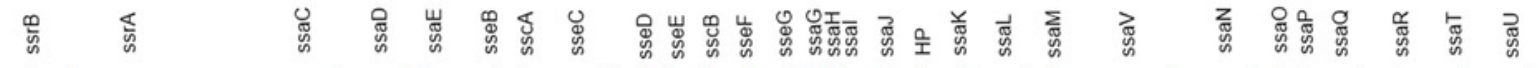

)

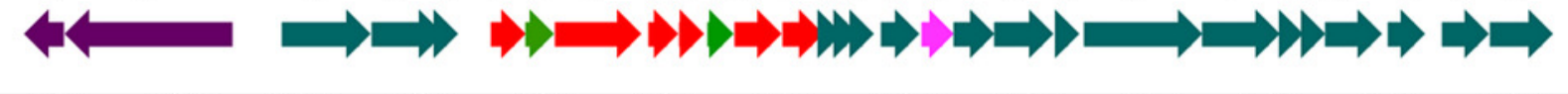

C)
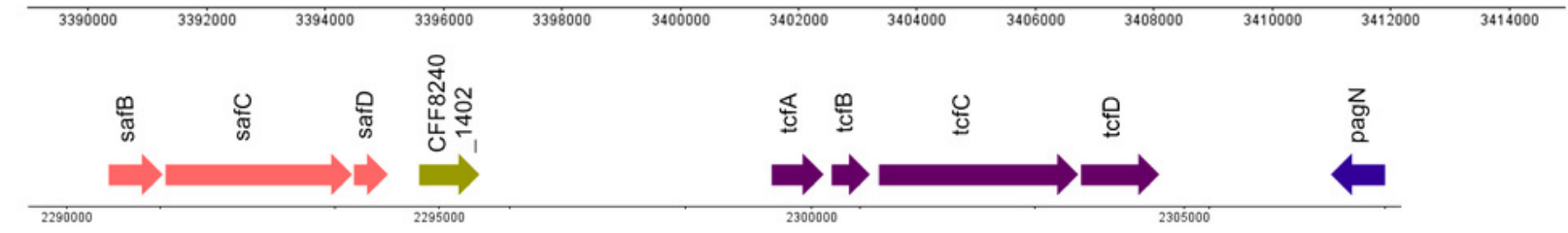

D)

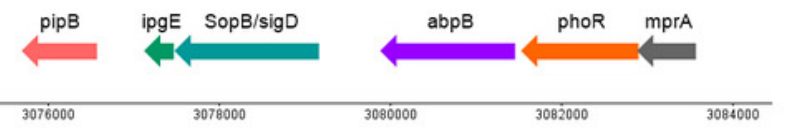

E)
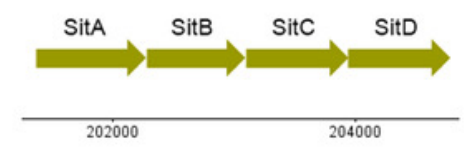

F)

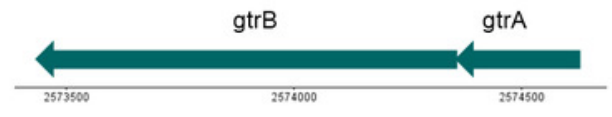


Figure 5

The distribution of CRISPR-Cas system in S. Stanley UPM 517 genome.

The genetic organization of CRISPR and its associated protein represents Type I-E subsytem.

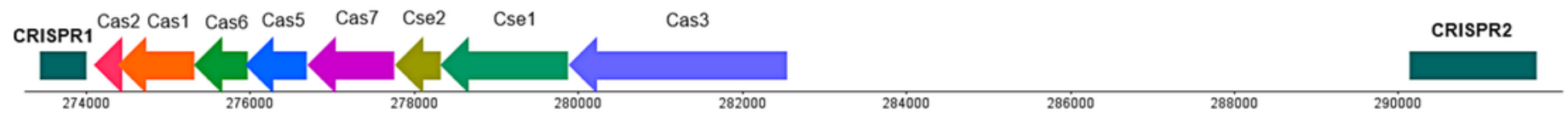

